\title{
Diagnostic of COVID-19: Chest Computer Tomography or RT-PCR?
}

\author{
ISI-SENAI-CIMATEC Group ${ }^{1^{*}}$ \\ ${ }^{1}$ Salvador, Bahia, Brazil
}

In this review article, we presented a gold-standard method to detect the SARS-CoV-2, the novel virus that is causing the COVID-19 outbreak, and the use of a computer tomography (CT) method to detect the complications of the disease. We showed the controversial analysis about which method is the best to detect the disease earlier due to the COVID-19 complications. We searched the articles in the main database (PubMed/Medline, Elsevier Science Direct, Scopus, Isi Web of Science, Embase, Excerpta Medica, UptoDate, Lilacs, Novel Coronavirus Resource Directory from Elsevier), in the high-impact international scientific Journals (Scimago Journal and Country Rank - SJR - and Journal Citation Reports - JCR), such as The Lancet, Science, Nature, The New England Journal of Medicine, Physiological Reviews, Journal of the American Medical Association, Plos One, Journal of Clinical Investigation, and in the data from Center for Disease Control (CDC), National Institutes of Health (NIH), National Institute of Allergy and Infectious Diseases (NIAID) and World Health Organization (WHO). We prior selected meta-analysis, systematic reviews, article reviews, and original articles in this order. We reviewed 96 articles and used 45 from March to June 2020, using the terms coronavirus, SARS-CoV-2, novel coronavirus, Wuhan coronavirus, severe acute respiratory syndrome, 2019-nCoV, 2019 novel coronavirus, n-CoV-2, covid, n-SARS-2, COVID-19, corona virus, coronaviruses, RT-PCR, computer tomography (CT), diagnostic methods, with the tools MeSH (Medical Subject Headings), AND, OR, and the characters $[, 6, ; / .$, to ensure the best review topics. We concluded that chest CT plays an important role in the timely detection of lung infection abnormalities in the early phase of COVID-19 infection. However, the RT-PCR is the gold standard method to detect SARS-CoV-2. Keywords: COVID-19. SARS-CoV-2. RT-PCR. CT.

\section{Introduction}

There is a current worldwide outbreak of a new type of coronavirus (2019-nCoV), which spreads to all over the world affecting 5,555,691 people and killing 348,541 (May 25, 2020) [1, 2]. On December 31, 2019, the China Health Authority reported the World Health Organization (WHO) to several cases of pneumonia of unknown reasons in Wuhan, Hubei province, China. The epidemiological evidence reveals that the cases originated from a seafood wholesale market in Wuhan, where poultry, snake, bats, and other live animals were on sale $[3,4]$. The gene's sequence of the virus was similar to that identified in bats $[5,6]$. On January 7,2020 , this disease was found to be the cause of a new severe acute respiratory Received on 2 March 2020; revised 9 June 2020.

Address for correspondence: ISI-SENAI CIMATEC. Av. Orlando Gomes, 1845, Piatã. Zip Code: 41650-010. Salvador, Bahia, Brazil. E-mail: jbth@jbth.com.

J Bioeng. Tech. Appl. Health (D) 2020 by SENAI CIMATEC. syndrome coronavirus 2 (SARS-CoV-2; previously known as 2019-nCoV [7] and formally named by the World Committee on Virus Classification) [8]. At the beginning of February 2020, the disease caused by this virus was named as Coronavirus Disease 2019 (COVID-19) by the World Health Organization (WHO) [9].

As the virus spreads quickly around the world affecting the lives of all people, the diagnostics play an important role in the containment of COVID-19, due to enabling the rapid implementation of control measures that limit the spread through case identification, isolation, and contact tracing [10].

The symptoms of COVID-19 are nonspecific and cannot be used for an accurate diagnosis. Many of these symptoms could be associated with other respiratory infections, such as fever, cough, fatigue, sputum production, and shortness of breath [11]. So, the gold standard method for COVID-19 is RTPCR. However, this method brings some intrinsic problems and chest CT scans have been used for diagnosing and screening COVID-19. However, our question is about which one of these methods is the best for diagnostic COVID-19? 
This review aimed to reproduce the recent studies about the diagnostic of COVID-19, elucidating the diagnostic performance measures, including predictive values, chest CT and initial reverse transcriptase-polymerase chain reaction (RT-PCR).

\section{The RT-PCR for COVID-19}

\section{Genome Sequence (GenBank)}

The development of molecular techniques is dependent upon understanding [12] the proteomic and genomic composition of the pathogen or the induction of changes in the expression of proteins/ genes in the host during and after infection [13]. The first genome sequence of SARS-CoV-2 was conducted with metagenomic RNA sequencing, an unbiased and high-throughput method of sequencing multiple genomes [14-17]. The sequence was done and added to the GenBank sequence repository on January 10, 2020 [15, 16].

\section{$\underline{\text { Nucleic Acid Test for SARS-CoV-2 }}$}

According Udugama and colleagues [14], nucleic acid testing is the primary method of diagnosing COVID-19 [18]. Several reverse transcription-polymerase chain reaction (RTPCR) kits have been designed to detect SARSCoV-2 genetically [14]. RT-PCR involves the reverse transcription of SARS-CoV-2 RNA into complementary DNA (cDNA) strands, followed by amplification of specific regions of the Cdna $[19,20]$. The design process generally involves two main steps:

1. The sequence alignment and primer design, and

2. Assay optimization and testing.

Corman and colleagues [21] analyzed several SARS-related viral genome sequences to design a set of primers and probes. From SARS-related viral genomes, they found three regions that had conserved sequences:

1. The RdRP gene (RNA-dependent RNA polymerase gene) in the open reading frame ORF1ab region;
Figure 1. SARS-CoV-2 morphology and the proteins (conserved sequences).

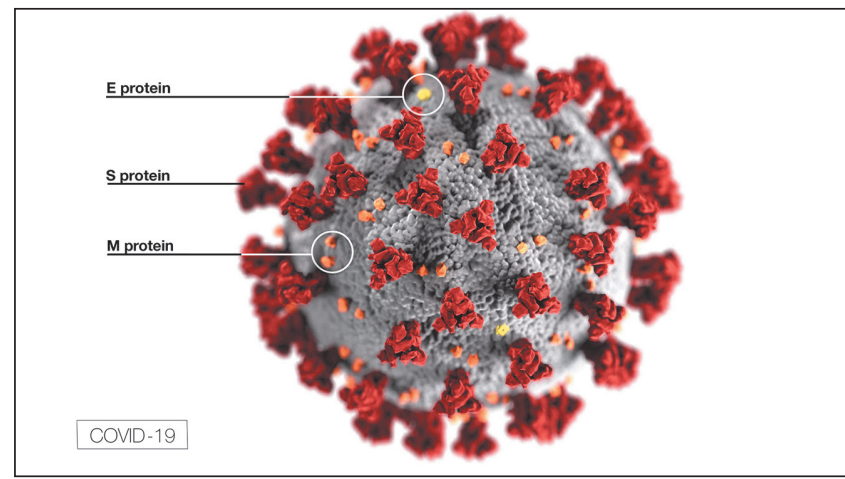

Credit/Source: This illustration, created at the Centers for Disease Control and Prevention (CDC), reveals ultrastructural morphology exhibited by coronaviruses. The illness caused by this virus has been named coronavirus disease 2019 (COVID-19). (CDC Illustration).

2. The E gene (envelope protein gene), and

3. The $\mathrm{N}$ gene (nucleocapsid protein gene). Both the RdRP and E genes had high analytical sensitivity for detection (technical limit of detection of 3.6 and 3.9 copies per reaction), whereas the $\mathrm{N}$ gene provided poorer analytical sensitivity (8.3 copies per reaction) (Figure 1).

RT-PCR can be performed by one- or two-steps assay [14]:

1. One-step assay: reverse transcription and PCR amplification are consolidated into one reaction. This assay format can provide rapid and reproducible results for high throughput analysis. But, the challenge is the difficulty in optimizing the reverse transcription and amplification steps as they occur simultaneously, which leads to lower target amplicon generation. The United States Centers for Disease Control and Prevention (CDC) uses a one-step real-time (RT-PCR) assay, which provides quantitative information on viral loads, to detect the presence of SARS-CoV-2 [22].

2. Two-step assay: This assay format is more sensitive than the one-step assay, but it is more time consuming and requires optimizing additional parameters. Lastly, controls need to be carefully selected to ensure the reliability of the assay and to identify experimental errors [23,24]. 
Workflow for Nucleic Acid Testing for SARS$\underline{\mathrm{CoV}-2}$

The National Medical Products Administration (NMPA) has approved at least 11 nucleic-acid-based methods and eight antibody detection kits in China for detecting SARS-CoV-2 [25].

\section{Performance}

The viral RNA is extracted and added to a master mix, which contains nuclease-free water, forward and reverse primers, a fluorophorequencher probe, and a reaction mix (consisting of reverse transcriptase, polymerase, magnesium, nucleotides, and additives) [14, 18]. The master mix and extracted RNA are loaded into a PCR thermocycler, and the incubation temperatures are set to run the assay. The $\mathrm{CDC}$ has recommended cycling conditions for RT-PCR. During RT-PCR, the fluorophore-quencher probe is cleaved, generating a fluorescent signal. The fluorescent signal is detected by the thermocycler, and the amplification progress is recorded in real-time. This reaction takes $\sim 45 \mathrm{~min}$ and can occur in a 96-well plate, where each well contains a different sample or control. There must be both a positive and negative control to interpret the final results properly when running RT-PCR. For SARS-CoV-2, the CDC provides a positive control sequence called nCoVPC [22].

Udugama and colleagues [14] listed many SARS-CoV-2 RT-PCR primers and probes from different research groups and agencies (Table $1)$.

\section{CT x RT-PCR}

Molecular techniques are more appropriate than chest $\mathrm{CT}$ scans for accurate diagnoses for COVID-19 because they can target and identify specific pathogens. The RT-PCR is the gold-standard method to detect COVID-19
[6]. However, the high false-negative rate, especially in the early stage of the outbreak, or because RT-PCR can be affected by low patient viral load and improper clinical sampling and transportation, and the lack of RT-PCR assay limited the timely diagnosis of infected patients [26-30]. Recent reviews showed that CT may have higher sensitivity (98\%) of chest CT [31] for diagnosis of COVID-19 than initial RT-PCR [32,33], especially when the signs of COVID-19 pneumonia is present, such as ground-glass opacities (GGO) (presenting in $100 \%$ of cases), GGO pattern, GGO location, consolidation, multilobe involvement, bilateral distribution, location of consolidation or GGO, pulmonary nodules surrounded by GGO, interlobular septal thickening, air bronchogram, halo sign, presence of cavitation, bronchial wall thickening, bronchiectasis, perilesional vessel diameter, lymphadenopathy (defined as lymph node with short-axis $>10 \mathrm{~mm}$ ), pleural and pericardial effusion. On chest CT, groundglass opacities (GGO) were present in 100\% of patients with RT-PCR confirmed COVID-19 (Figure 2) [34-37].

Thereby, CThas becomean importantimaging method for the early detection of patients with COVID-19 pneumonia [28, 34]. Nevertheless, the specificity of CT is low (56\%) [31] due to the nonspecific findings of COVID-19 that overlap with those of other viral pneumonia, and the images cannot distinguish between COVID-19 pneumonia and other viruses' pneumonia [34, 35]. Also, some patients present a positive RTPCR test for COVID-19 and normal CT, as well as early negative RT-PCR and positive CT for COVID-19 pneumonia [35, 37, 38].

There is a critical issue that the physicians have to consider: the large volume of workload for hospital staff and difficulties with disinfection procedures are non-negligible issues related to the widespread use of CT as a diagnostic tool for COVID-19. Recently, the Society of Thoracic Radiology and American Society of Emergency Radiology jointly released a position statement 
Table 1. Primers for SARS-CoV-2 (PCR).

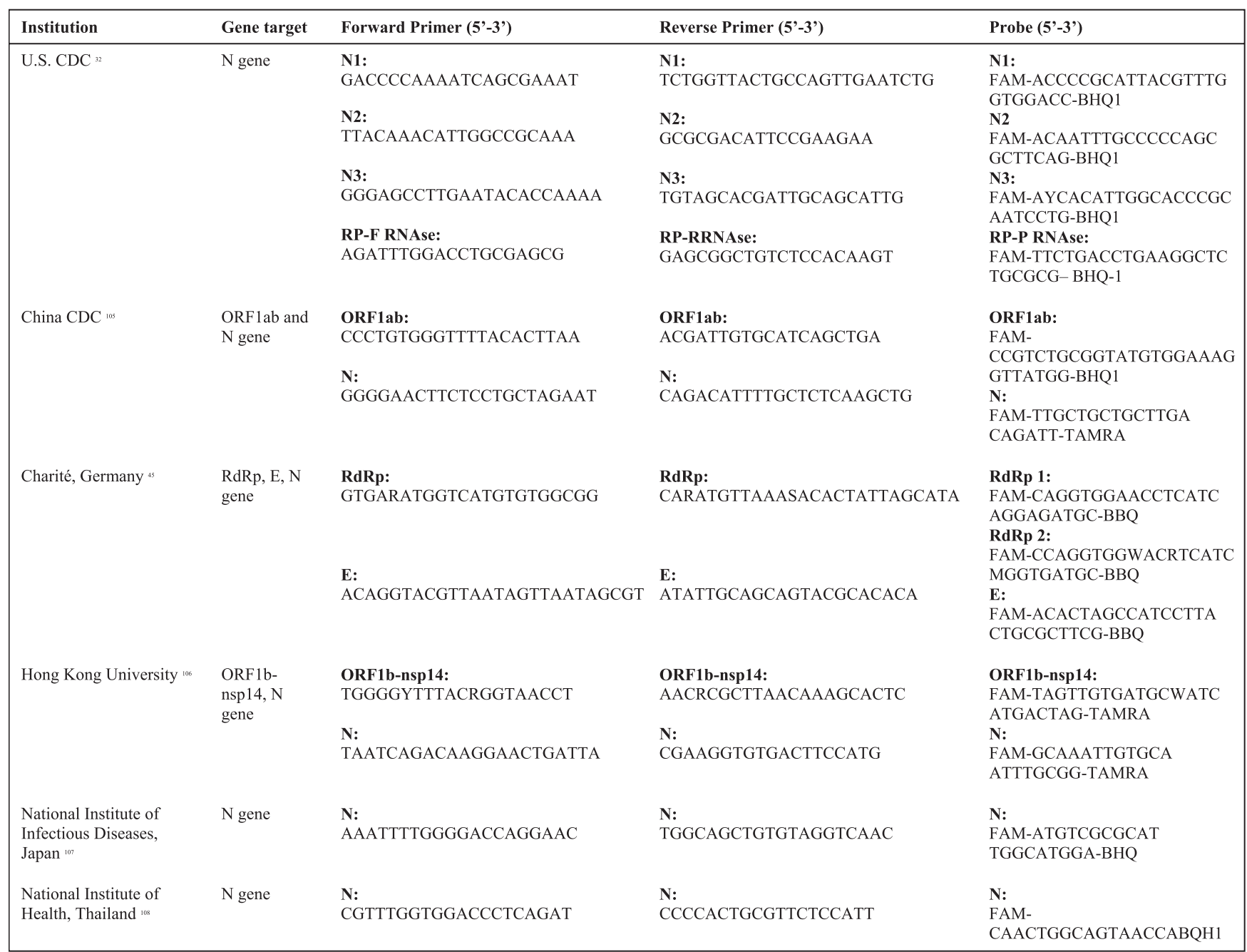

Credit/Source: Udugama and colleagues [14].

according to which routine CT screening is not recommended for the diagnosis of patients under investigation for COVID-19 [37, 39, 40].

However, besides the specificity (56\%) [31] and the described issues about chest CT in this review, this new diagnostic was included in the management of patients to ensure timely treatment and isolation measures due to the delays of RT-PCR testing and the large group of patients with respiratory symptoms by COVID-19 [18, 31, 36, 37]. So, a combination of chest CT and repeat RT-PCR testing may be beneficial for the diagnosis of COVID-19 in the setting of strong clinical suspicion [36].

\section{Discussion}

Xie and colleagues [32] and Huang and colleagues [41] indicated that many positive cases for COVID-19 present initially negative RT-PCR tests, but lung abnormal lesions detected by chest CT. Fang and colleagues [33] found that $98 \%$ of the patients already presented positive CT pneumonia while $71 \%$ of the patients had initially positive RT-PCR results. They also demonstrated that the sensitivity of chest CT was higher than RT-PCR. Moreover, $\mathrm{Ai}$ and colleagues [34] concluded that chest CT had a high sensitivity for the diagnosis of 
Figure 2. Chest CT scans presenting the spectrum of findings of COVID-19.

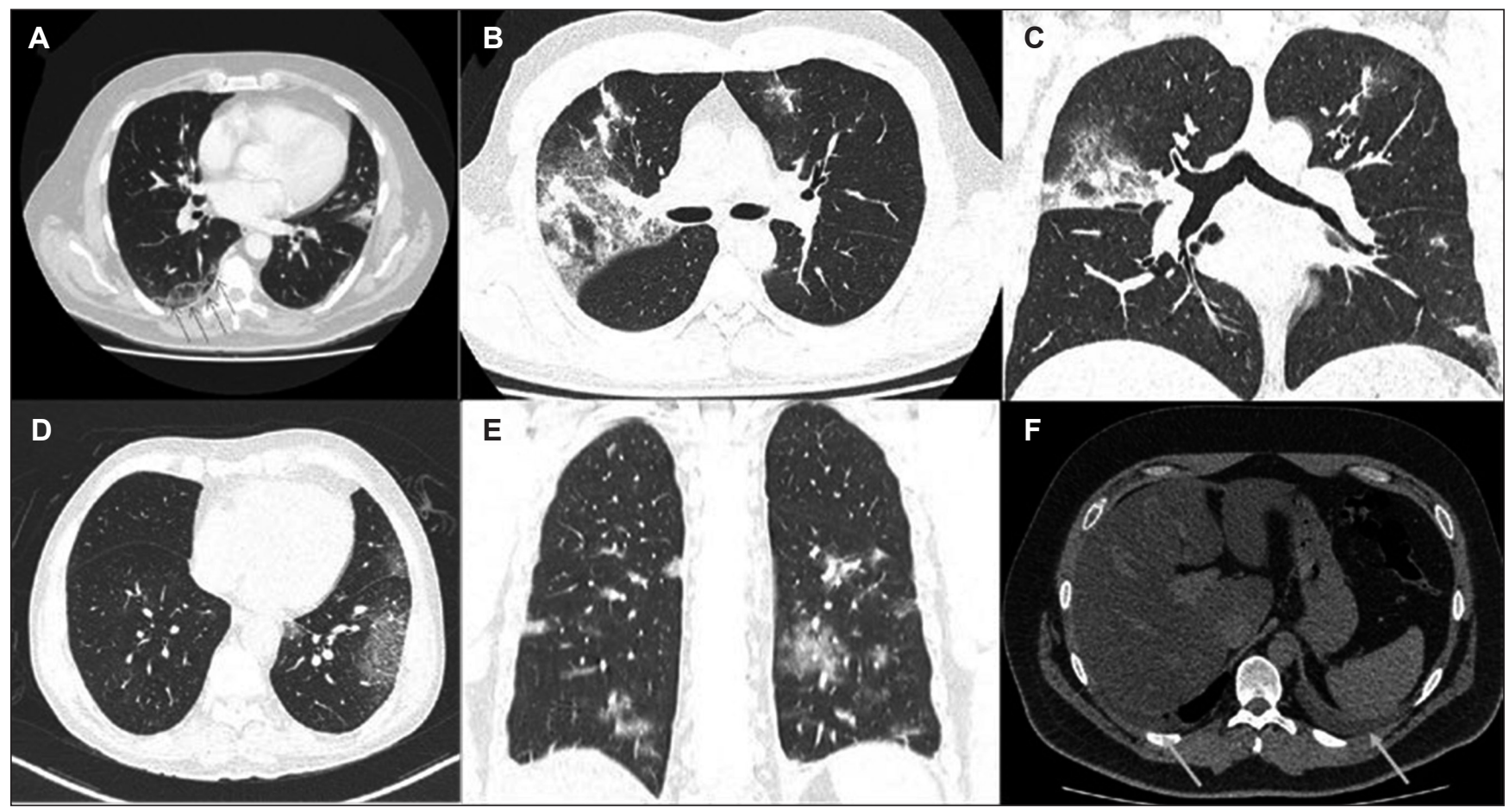

Credit/Source: Adapted from Chate and colleagues (2020) [38]. A-F. Besides the Figure presents many findings of COVID-19 pneumonia, in all CT images the ground-glass opacities are present.

COVID-19 than RT-PCR. They tested patients by RT-PCR assay and chest CT scanning on the same day and found that the patients who initially had negative RT-PCR results, presented positive CT abnormalities. However, they also found RTPCRpositive patients with clinical symptoms had normal CT scans. Similarly, Chung and colleagues [35] in a retrospective study found patients who showed negative findings on first-time chest CT, but positive-RT-PCR, for whom a follow-up chest $\mathrm{CT}$ revealed positive findings later. Furthermore, $\mathrm{Xu}$ and colleagues [8] reported that first-time baseline chest CT did not show any abnormalities in $23 \%$ of the patients. Similarly, Pan and colleagues [42] reported patients with first normal CT had lung abnormalities on the follow-up CT approximately 4 days later. Besides that, the chest CT was included in the new diagnostic criteria in combination with RT-PCR for confirmation of COVID-19 pneumonia diagnosis if it is narrowly indicated for fast management of the disease due to the cost-benefit for the patient [3, 7, 31, 38, 41-43].

\section{Conclusion}

We concluded that chest CT plays an important role in the timely detection of lung infection abnormalities in the early phase of COVID-19 infection. Concerning the diagnosis of COVID-19, a combination of RT-PCR screening and chest CT scanning in the highly suspected patients might be a complementary diagnostic for COVID-19. Nevertheless, RTPCR remains the reference standard for the final diagnosis of COVID-19 infection despite the false-negative rate. The physicians should be vigilant at all times to identify patients with COVID-19 infection, who may have few or no clinical symptoms, normal chest CT, and or even initial negative PR-PCT test.

\section{References}

1. COVID-19 Map - Johns Hopkins Coronavirus Resource Center. https://coronavirus.jhu.edu/map.html [Acessed May 25, 2020]. 
2. Wu F, Zhao S, Yu B, Chen Y-M, Wang W, Song Z-G, et al. A new coronavirus associated with human respiratory disease in China. Nature 2020.

3. $\mathrm{Hu} \mathrm{L}$, Wang $\mathrm{C}$. Radiological role in the detection, diagnosis and monitoring for the coronavirus disease 2019 (COVID-19). European Review for Medical and Pharmacological Sciences 2020;24:4523-4528.

4. Cheng ZJ, Shan J. 2019 Novel coronavirus: where we are and what we know. Nature 2020. https://doi.org/10.1007/ s15010-020-01401-y.

5. Li W, Shi Z, Yu M, Ren W, Smith C, Epstein JH, Wang H, Crameri G, Hu Z, Zhang H. 2005. Bats are natural reservoirs of SARS-like coronaviruses. Science. 310(5748):676-679.

6. Lu R, Zhao X, Li J, Niu P, Yang B, Wu H, Wang W, Song $\mathrm{H}$, Huang B, Zhu N, et al. Genomic characterisation and epidemiology of 2019 novel coronavirus: implications for virus origins and receptor binding. Lancet 2020;395(10224):565-574.

7. Chen N, Zhou M, Dong X, Qu J, Gong F, Han Y, Qiu Y, Wang J, Liu Y, Wei Y, Xia J, Yu T, Zhang X, Zhang L. Epidemiological and clinical characteristics of 99 cases of 2019 novel coronavirus pneumonia in Wuhan, China: a descriptive study. Lancet 2020;395: 507-513.

8. Xu X, Yu C, Qu J, Zhang L, Jiang S, Huang D, Chen B, Zhang Z, Guan W, Ling Z, Jiang R, Hu T, Ding Y, Lin L, Gan Q, Luo L, Tang X, Liu J. Imaging and clinical features of patients with 2019 novel coronavirus SARS-CoV-2. Eur J Nucl Med Mol Imaging 2020;47:1275-1280.

9. Jin $\mathrm{YH}$, Cai L, Cheng ZS, et al. A rapid advice guideline for the diagnosis and treatment of 2019 novel coronavirus [2019-nCoV] infected pneumonia [standard version]. Mil Med Res 2020;7:4.

10. Zhu N, Zhang D, Wang W, Li X, Yang B, Song J, Zhao X, Huang B, Shi W, Lu R, et al. A novel coronavirus from patients with pneumonia in China, 2019. N Engl J Med 2020;382(8):727-733.

11. Guan W-J, Ni Z-Y, Hu Y, Liang W-H, Ou C-Q, et al. Clinical characteristics of coronavirus disease 2019 in China. N Engl J Med 2020. Doi: 10.1056/NEJMoa2002032.

12. Zhou P, Yang X-L, Wang X-G, Hu B, Zhang L, Zhang W, Si H-R, Zhu Y, Li B, Huang C-L, et al. A pneumonia outbreak associated with a new coronavirus of probable bat origin. Nature 2020;579:270.

13. Report of the WHO-China Joint Mission on Coronavirus Disease 2019 (COVID-19); WHO: Geneva, Switzerland, 2020.

14. Udugama B, Kadhiresan P, Kozlowski H, Malekjahani A., Osborne M, Li V, Chen H, Mubareka S, Gubbay J, Chan W. Diagnosing COVID-19: The Disease and Tools for Detection. ACSNano; 2020. https://dx.doi.org/10.1021/ acsnano.0c02624

15. Sheridan C. Coronavirus and the race to distribute reliable diagnostics. Nat Biotechno. 2020, Doi: 10.1038/d41587020-00002- 2 .

16. Vase G, Mansourian M, Karimi R, Heshma GK,Baradaran MS, Pezeshki A, Atae B, Zandifa A, Shafaa O, Haghjoo JS. Clinical characterization and chest CT findings in laboratory-confirmed COVID-19: a systematic review and meta-analysis. medRxiv 2020. Doi: 10.1101/2020.03.05.20031518.
17. Miller S, Chiu C, Rodino KG, Miller MB. Pointcounterpoint: should we be performing metagenomic nextgeneration sequencing for infectious disease diagnosis in the clinical laboratory? J Clin Microbiol 2020. Doi: 10.1128/ JCM.01739-19.

18. CDC 2019-Novel Coronavirus (2019-nCoV) Real-Time RT-PCR Diagnostic Panel; Division of Viral Diseases, U.S. Centers for Disease Control and Prevention: Atlanta, GA, 2020.

19. Freeman WM, Walker SJ, Vrana KE. Quantitative RT-PCR: pitfalls and potential. BioTechniques 1999;26(1):124-125.

20. Kageyama T, Kojima S, Shinohara M, Uchida K, Fukushi S, Hoshino FB, Takeda N, Katayama K. Broadly reactive and highly sensitive assay for Norwalk-like viruses based on real-time quantitative reverse transcription-PCR. J Clin Microbiol 2003;41(4):1548-1557.

21. Corman V, Bleicker T, Brünink S, Zambon M. Diagnostic detection of Wuhan coronavirus 2019 by real-time RTPCR. World Health Organization: Geneva, 2020.

22. CDC. Research Use Only Real-Time RT-PCR Protocol for Identification of 2019-nCoV; Centers for Disease Control and Prevention. https:// www.cdc.gov/coronavirus/2019ncov/lab/rt-pcr-detectioninstructions. html.

23. Wong ML, Medrano JF. Real-time PCR for mRNA quantitation. BioTechniques 2005;39(1):75-85.

24. Bustin SA. A-Z of quantitative PCR. International University Line: San Diego, CA, 2004.

25. State Food and Drug Administration emergency approval of new coronavirus detection products; China National Medical Products Administration. http://www.nmpa.gov. cn/WS04/CL2056/375802. html.

26. Prinzi A. False negatives and reinfections: the challenges of SARS-CoV-2 RT-PCR testing. American Society for Microbiology May 2020.

27. Chan JF, Yuan S, Kok KH, To KK, Chu H, Yang J, Xing F, Liu J, Yip CC, Poon R W, Tsoi HW, Lo SK, Chan KH, Poon VK, Chan WM, Ip JD, Cai JP, Cheng VC, Chen H, Hui CK, Yuen KY. A familial cluster of pneumonia associated with the 2019 novel coronavirus indicating person-to-person transmission: a study of a family cluster. Lancet 2020; 395 : 514-523.

28. Rodriguez-Morales AJ, Cardona-Ospina JA, GutiérrezOcampo E, Villamizar-Peña R, Holguin-Rivera Y, et al. Clinical, laboratory and imaging features of COVID-19: A systematic review and meta-analysis. Travel Medicine and Infectious Disease 2020;34. https://doi.org/10.1016/j. tmaid.2020.101623.

29. Peiris JS, Chu CM, Cheng VC, Chan KS, Hung IF, Poon LL, Law KI, Tang BS, Hon TY, Chan CS, Chan KH, Ng JS, Zheng B J, Ng W L, Lai RW, Guan Y, Yuen KY. Clinical progression and viral load in a community outbreak of coronavirus-associated SARS pneumonia: a prospective study. Lancet 2003;361:1767-72.

30. Hui A. Severe acute respiratory syndrome: historical, epidemiologic, and clinical features. Infect Dis Clin North Am 2019; 33: 869-889.

31. Caruso D, Zerunian M, Polici M, et al. Chest CT features of COVID-19 in Rome, Italy. Radiology 2020. doi: 10.1148/ radiol.2020201237. 
32. Xie X, Zhong Z, Zhao W, Zheng C, Wang F, Liu J. Chest CT for typical 2019-nCoV pneumonia: relationship to negative RT-PCR testing. Radiology 2020:200343.

33. Fang Y, Zhang H, Xie J, Lin M, Ying L, Pang P, Ji W. Sensitivity of chest CT for COVID-19: comparison to RTPCR. Radiology 2020:200432.

34. Ai T, Yang Z, Hou H, Zhan C, Chen C, Lv W, Tao Q, Sun Z, Xia L. Correlation of chest CT and RT-PCR testing in coronavirus disease 2019 (COVID-19) in China: a report of 1014 cases. Radiology 2020:200642.

35. Chung M, Bernheim A, Mei X, Zhang N, Huang M, Zeng X, Cui J, Xu W, Yang Y, Fayad Z A, Jacobi A, Li K, Li S, Shan H. CT imaging features of 2019 novel coronavirus (2019-nCoV). Radiology 2020; 295: 202207.

36. Hyungjin K, Hyunsook H, Soon HY. Diagnostic performance of $\mathrm{CT}$ and reverse transcriptase-polymerase chain reaction for coronavirus disease 2019: a metaanalysis. Radiology May 2020.

37. Bernheim A, Mei X, Huang M, et al. Chest CT Findings in Coronavirus Disease-19 (COVID-19): Relationship to Duration of Infection. Radiology 2020 Feb 20:200463.
38. Chate RC, Fonseca EKUN, Passos RBD, Teles GBS, Shoji $\mathrm{H}$, Szarf G. Presentation of pulmonary infection on CT in COVID-19: initial experience in Brazil. J Bras Pneumol 2020;46(2):e20200121. https://dx.doi.org/10.36416/18063756/e20200121.

39. STR/ASER COVID-19 position statement. https:// thoracicrad.org.

40. Loong TW. Understanding sensitivity and specificity with the right side of the brain. BMJ 2003;327(7417):716-719.

41. Huang P, Liu T, Huang L, et al. Use of chest CT in combination with negative RT-PCR assay for the 2019 Novel Coronavirus but high clinical suspicion. Radiology 2020; 295: 22-23.

42. Pan Y, Guan H. Imaging changes in patients with 2019nCov. Eur Radiol 2020. doi: 10.1007/s00330-020-06713-z.

43. Song F, Shi N, Shan F, et al. Emerging 2019 novel coronavirus (2019-nCoV) pneumonia. Radiology 2020; 295:210-217.

44. Shi H, Han X, Jiang N, et al. Radiological findings from 81 patients with COVID-19 pneumonia in Wuhan, China: a descriptive study. Lancet Infect Dis 2020;20:425-434.

45. Kanne JP. Chest CT. Findings in 2019 novel coronavirus (2019-nCoV) infections from Wuhan, China: key points for the radiologist. Radiology 2020;295: 16-17. 